\title{
Maintaining the Abstract Critical Facility in Post-Digital Drawing Practice
}

\author{
Mike Davis
}

\section{Introduction}

Drawing practice has been significantly and irrevocably augmented through the advent of digital technologies. The term "post-digital" refers to a condition in which those technologies have been subsumed into the suite of tools at the disposal of designers. Such a condition renders the polemic of traditional versus new media, of pencil versus mouse, redundant. Building information model, diagram, render, collage, equation and script - each is understood as a form of drawing, each has its own predispositions and purposes. The qualities of the project that unfolds through the focused application of these tools is, as ever, a reflection of the abilities of designers to pursue ideas through drawing. And yet the "traditional versus digital" polemic, and the well-turned ground of the problem of the digital lying with its general tendency toward the production of visually-realistic images, is sustained by a lack of critical scrutiny based upon active engagement. With a critical base which relies solely upon observation grounded in conventional drawing, the digital remains "new" but somehow grows tired. This text proceeds on the understanding that what is required to address this broader concern is to accept the gift to drawing practice that its digital augmentation is and, through practical engagement, to deal with the related imperative of critically (re-)evaluating and (re-)negotiating the role that each tool plays in drawing practice, and indeed of developing understandings of relationships between tools.

This paper sets out to articulate a hybrid digital-analogue drawing practice operating in a design project. It does so through a discussion of a preliminary design proposal for a new factory complex for Ecostore - a producer of environmentallyfriendly household products - to be sited in Avondale, Auckland.

Stan Allen has argued that digital techniques operate indifferently in relation to established techniques, often with the effect of compromising the power of conceptualisation which was particular to traditional drawing.

... these techniques of visualization ignore what has traditionally given architectural representation its particular power of conceptualization - that is to say, its necessary degree of abstraction, the distance interposed between the thing and its representation. Design does not operate on the basis of resemblance, but on the basis of abstract codes and a complex instrumentality. (2009: 75)

Allen thus problematises digital visualisation techniques in relation to traditional architectural representation, in terms of their operation in the design process. 


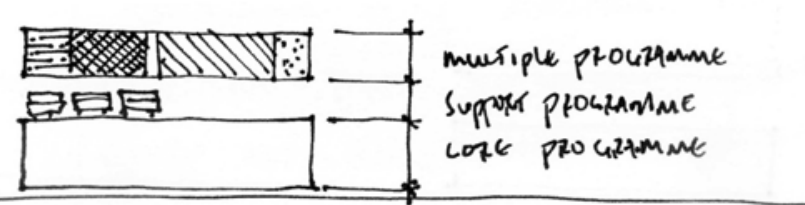

Sinbular poltanme

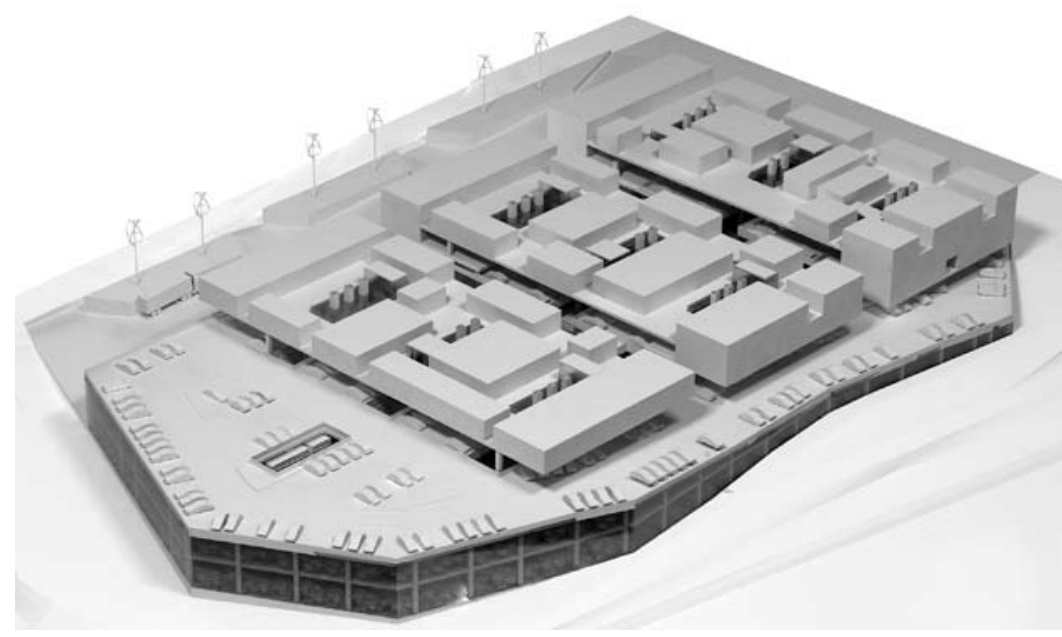

Fig. 2
Greg Lynn writes to similar effect when he defines the difference between an abstract machine (a diagram in the context of his discussion) and a concrete assemblage.

Concrete assemblages are mechanistic and already technical where abstract machines are conceptual statements with many possibilities for reconfiguration and transformation. (1998: 230)

The use of the term abstraction here is not intended to be confused with a purist or modern notion of abstraction. In those instances, abstraction involves a reduction to fixed formal essences - involving a kind of paring away. Instead, abstraction is used here in a more generative, evolutionary and productive manner - involving a kind proliferation, expansion and unfolding. (1998: 225)

While in their respective texts Allen is concerned with contrasting digital and analogue techniques, and Lynn is particularly concerned with the potential of the diagram in relation to design, this paper is concerned with post-digital drawing practice and the contingent relationships between the tools and techniques through which design is pursued. What it shares with Allen and Lynn is a concern for maintaining the abstract critical facility of drawing and, through this, pursuing explorative design processes.

The Ecostore project demonstrates five strategies for the maintenance of the abstract critical facility of drawing. They have been apprehended via a reflective interrogation of the making and outcome of the project. From these strategies three broader propositions are extrapolated with regard to post-digital drawing practices in architecture.

\section{Ecostore}

From Auckland's North Western Motorway the Ecostore factory complex reads as a vegetative wedge extruded from the site, above which are suspended three timber-clad and perforated blocks of equal widths but varying heights.

Each block is the output of a projected stage in the development. Conversely, the programmatic imperatives and opportunities of the project are vertically stacked - office over carpark over factory on site. This spatial condition of separation renders the necessary connection of these programmatically-related elements problematic and thematic to the project.

The complex is a maximum built condition designed to utilise the maximum amount of space available on the site. It is a response to the conditions of its inception driven by a negotiation between regulations and requirements. The intention here is to discuss how the project developed through a demonstration
Fig. 1 Ecostore: aerial perspective of the digital mass model from the North East Fig. 2 Ecostore: programmatic imperatives 

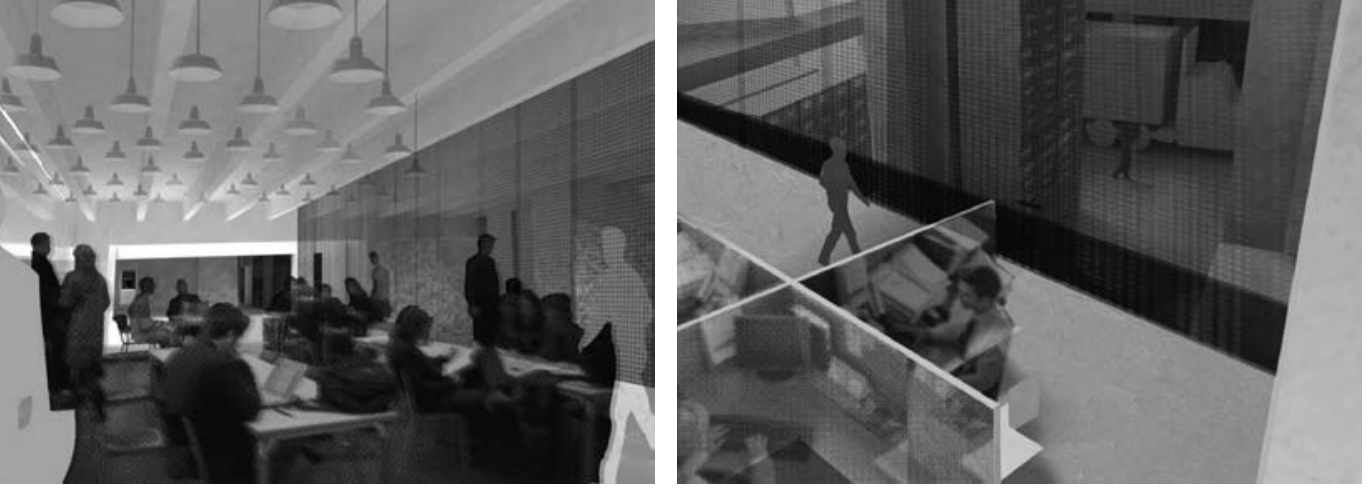

Fig. 3 Ecostore: interior collages

of the strategies that operated to maintain the abstract facility of drawing throughout this early phase of design.

\section{Strategy I: Specialise and collaborate}

The Ecostore project was developed to its current state through collaboration between Patrick Loo, Ian Scott and myself. Patrick's and Ian's demands for information about the project forced me (as project leader) to articulate and address - through drawing and modelling, in diagrams, AutoCad, foam and Rhinoceros - issues that I had been unable to see or had resisted addressing. The outcome of this intra-disciplinary endeavour is a preliminary design project that is understood as an open system intended to be further developed through the input of specialists, those with the necessary knowledge to bring it to a positive ecological and economic realisation. In this way the project retains a sense of the diagrammatic.

This paper works toward a proposition (Proposition 2: Shift content) to focus on the relationships between tools and techniques, toward developing a critical inter-instrumentality, a condition that requires both a depth of understanding (born of particular technical virtuosity) and yet ambivalence toward the tools and techniques concerned. But the passion required to take up the technical workload needed for designers to develop and maintain a depth of knowledge across the entire expanding raft of tools and techniques available precludes ambivalence, and tends to throw out the fragile balance between the development of technique and the development of the design. Yet the outcomes of these more technical specialisations are compelling. Collaborative design practices emerge out of this compulsion, with each collaborator operating with their chosen tool or technique to define their particular role in the design process. The effect is to resolve the paradox of understanding coupled with ambivalence.

\section{Strategy 2: Delay the "real", explore the possible}

Linguistic constructions are merely postponed, not abolished, and a regime of abstract, schematic statements are seen to pre-empt and sponsor them. From the particular discursive formation of multiple diagonally intersecting statements some form of expression emerges. (Lynn 1998: 227)

Design might be understood as a search (facilitated by drawing and making practices) for resonances between the conditions (site, brief, regulations...) and designed responses to those conditions. In Lynn's terms these resonances are instances of a "particular discursive formation of multiple diagonally intersecting statements" (Lynn 1998: 227).

There was a tacit recognition working through the Ecostore project that the deployment of digital visualisation techniques to produce visually-realistic images (visual realisms) would run the serious risk of dramatically reducing the potential for the emerging design proposition to develop substantially beyond the condition in which it was depicted in such a visual realism. In other words, the 


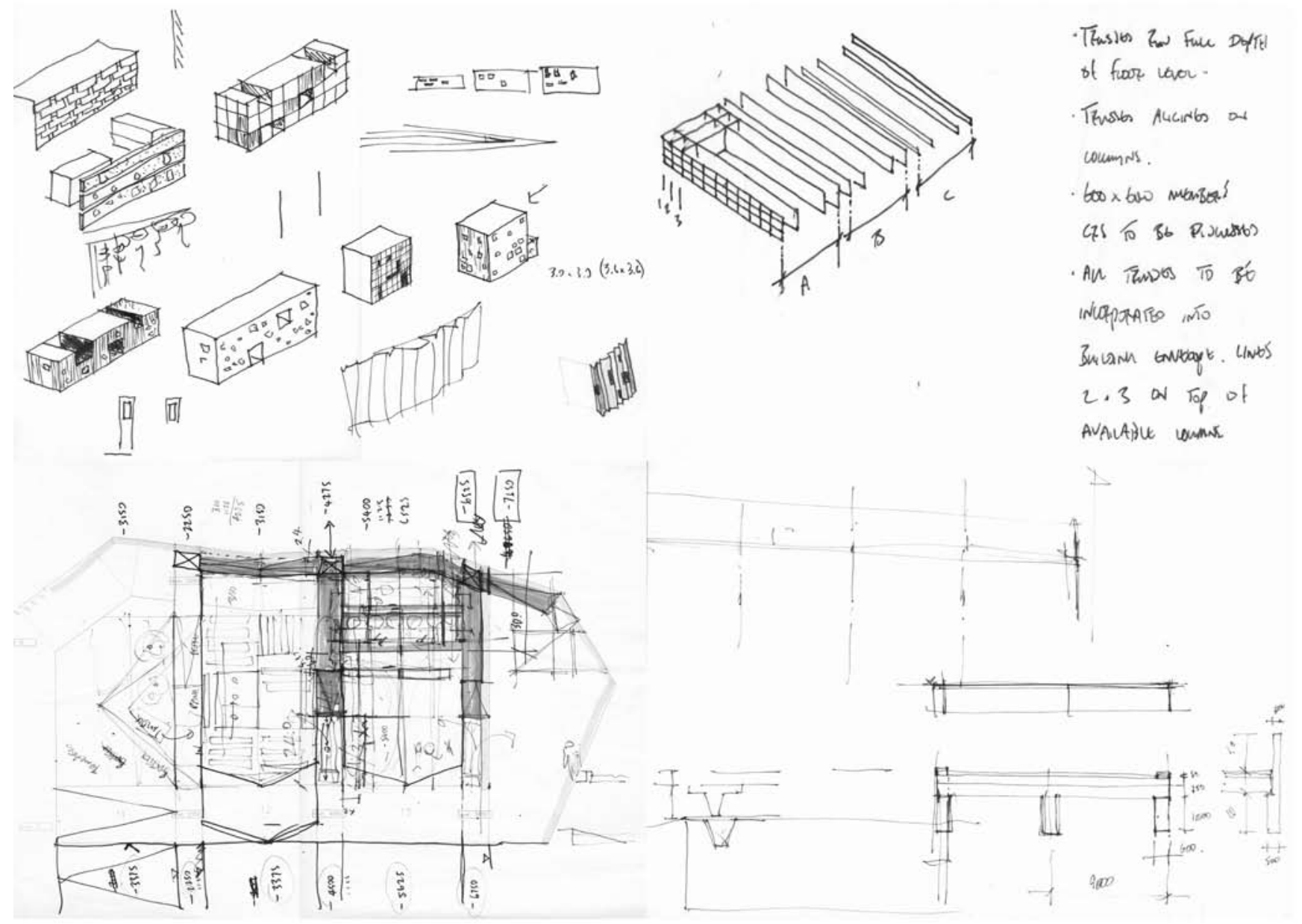

concern was that a visual realism introduced at this early stage of design could curtail the search for resonances sought through the design process.

Qualities of abstraction were consciously cultivated in the design process through the tools and techniques brought into play. These qualities were maintained through the design process to allow the design proposition to unfold in response to the conditions of its inception and development - those evident at the outset and those emerging through it. Abstraction was a means of delay, of creating space in time and of resisting the "real" so that the design proposition could develop, rather than be thrust forward and bound prematurely at any one point through the imposition of a photo-"real"-istic image.

The project is presented through differing disciplinary specific outcomes, each privileging a level of abstraction, and telling a different story or developing a different aspect of the project. The exploded isometric, the sections and the diagrams are abstract by nature; the aerial shots present an un-materialised mass; and the nature of the perspective collages, their rough-ness, the juxtaposition of the components and the resulting level of abstraction inhibits a sense of the "real" but they simultaneously project possible atmospheric qualities of the space in question (Allen 2009: 89).

Collectively the drawn outcomes suggest or invite extrapolation toward a whole proposition but do not default to a single image in order to do so. The effect is to keep the project in the realm of the possible rather than the predetermined.

\section{Strategy 3: Retain disciplinary specificity}

The purpose of the Ecostore preliminary presentation drawing is primarily to demonstrate a projected performance. What it provides are multiple means through which to do so. Each of the drawings selected for inclusion in the preliminary presentation drawing consciously retains its own specific role. What results is the framing of the space between the selected drawings as the space of potential productive differences. 

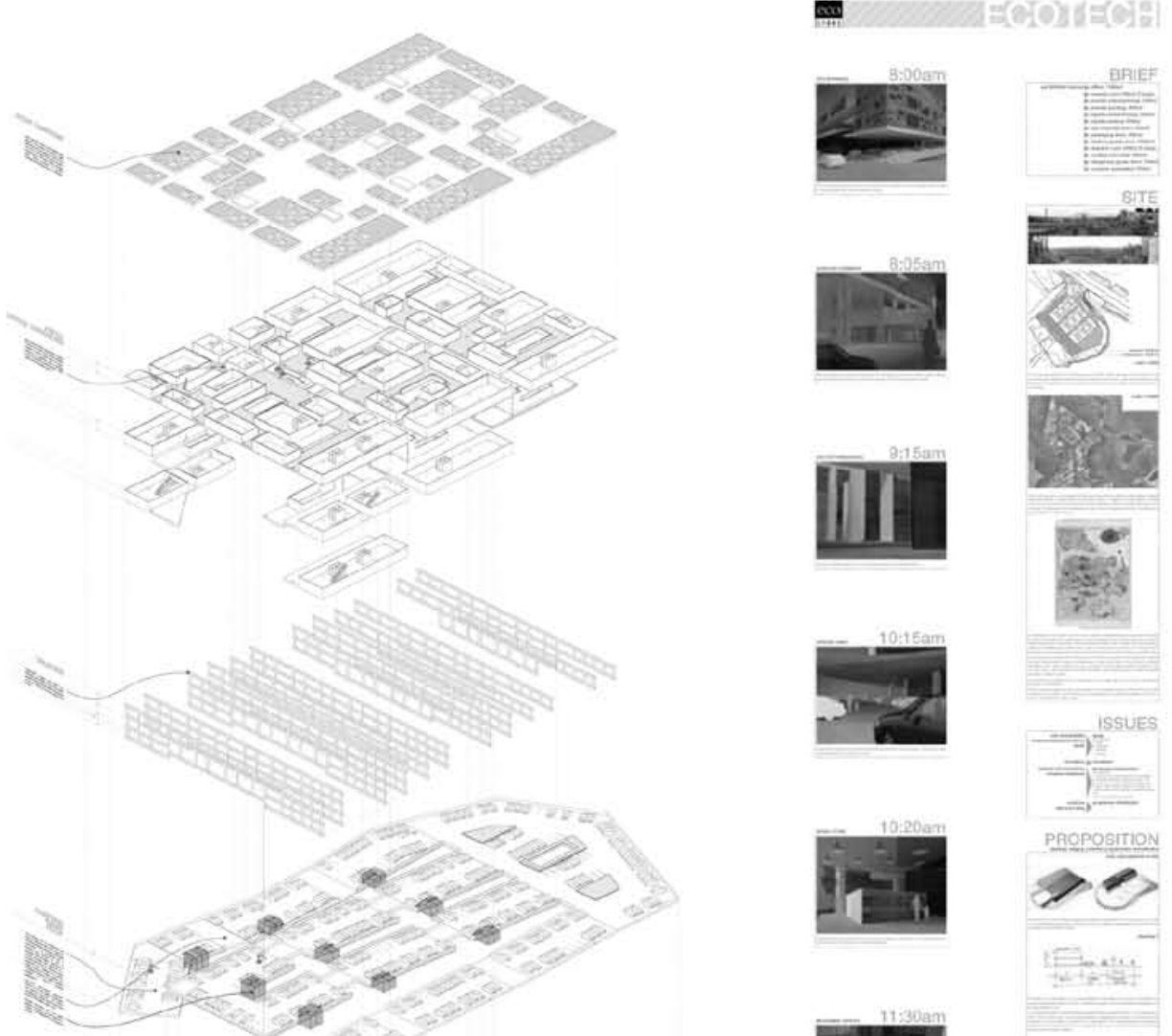

PHCPOSIIIOY
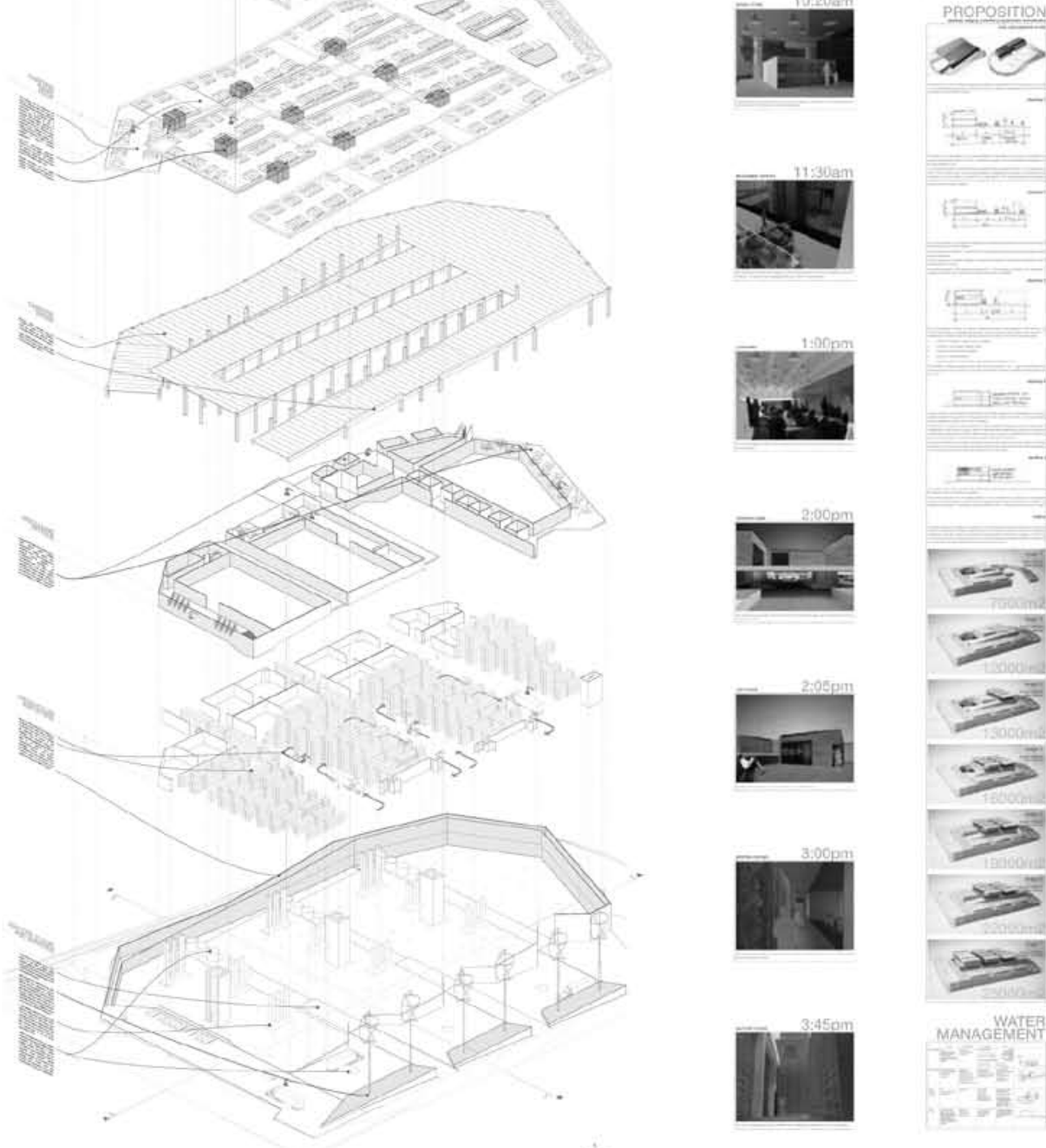

MANAGEMENT

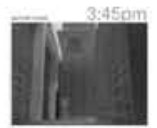

yin $=$ a

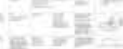
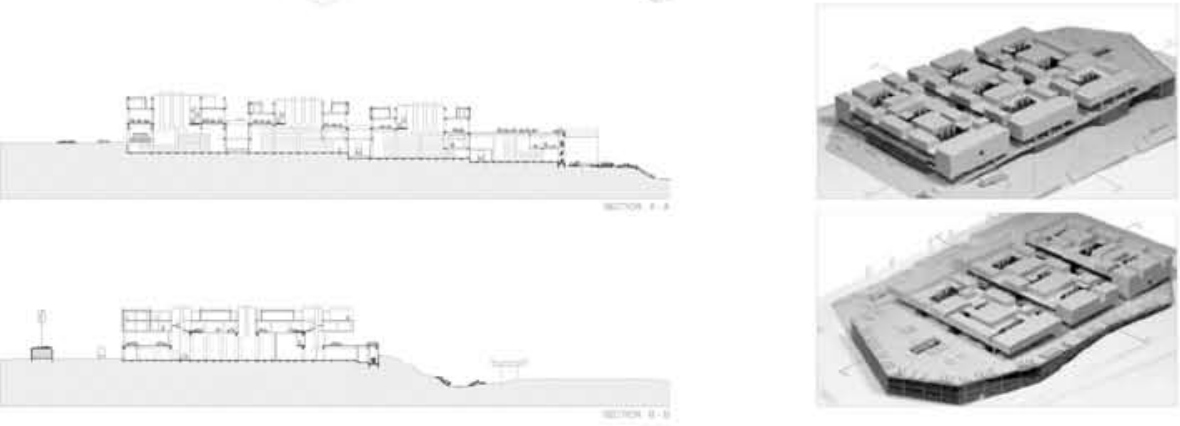
At the core of the content lies a detailed Rhinoceros model based upon twodimensional AutoCad plans and sections, which were based on drawings made on butter paper over outline templates or datums, taken from both AutoCad and Rhinoceros and physical models based upon the same. Tools and techniques were deployed according to their predispositions - to explore the advantages of each in the context of the project. For example, on the basis of a raft of more time-consuming physical foam models, Rhinoceros was used to quickly produce multiple iterations of one particular foam option. In this instance the physical model lent itself to the consideration of the larger formal issue, while the speed of modelling successive massing iterations in Rhinoceros lent itself more to the consideration of the next level of detail. In the same way AutoCad was used to project material into sections that in Rhinoceros would have been unnecessarily time-consuming and processor-intensive. The examples provided are not intended to give the impression of a linear, nor seamless, design process. On the contrary, the seams (the space between the tools and techniques) and the circularity of this design process were pronounced.

Selected drawings are arranged in strips: a Rhinoceros-based exploded isometric coupled with AutoCad-based sections, into which is keyed a perspectival narrative, and a sectional-diagram and model-based composite. At this early stage in the design process the different drawings are held in tension conceptually and graphically. They are not permitted to completely correspond with each other, slight discrepancies are embraced. This tension further retains in the project a sense of openness, of further exploration to be undertaken, of development to occur in response to the inevitable raft of impacts to be encountered as the project proceeds.

\section{Strategy 4: Aggregate drawings}

Traditionally the separate sheets of paper or film on the drawing board offered a repository of critical design thought developed and collected during the course of a project - sketches recorded the development of plan, section and elevation adorned the sheets containing the same. With the complex of tools and techniques designers now encounter there is no longer a core medium in which this repository may reside but the essential demand for it still exists.

With the Ecostore project the folders containing successive iterations of the Rhinoceros model and the AutoCad drawings were literally, digitally folded away and rendered opaque. Yet the knowledge they contained required exposure and evaluation to be useful in the development of the project. The project repository was established in a booklet format - the operative material document was the means to keep the material active.

The document served to process, record and present selected material, to work as an augmented repository of knowledge which existed separately from the media in which the content was originally produced. The secondary level of processing, of collating the content into booklet format, was the means to develop understandings of each facet of the project and their potential relationships to one another.

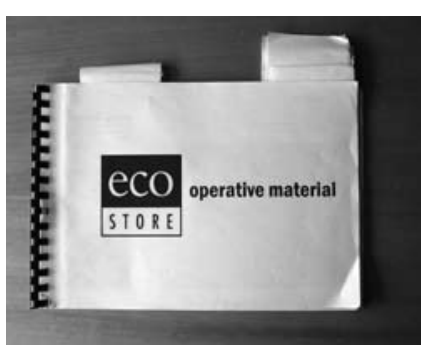

Fig. 6 Ecostore: operative material document 
Drawing (verb) still works not only to produce the representation of concept, not only to test and develop the concept, but to develop in the designer sensitivities to those resonances sought between project conditions and responses. The difference in a post-digital design environment is that drawing practices which do this work now consist of an expanding range of techniques in increasingly fluid relationships. Drawing no longer only has to do with using a single tool in multiple disciplinarily-bound ways to produce varying effects. Post-digital design practice has to do with the application of multiple tools, each producing fewer effects, and the management of the relationships between designers, tools and effects. In other words, the focus is shifted from particular tools to relationships between them. This amounts to a sort of "what if I cross this, with this, with this?" speculative approach to architectural drawing.

\section{Proposition 2: Shift content}

The concept of the "craft" of drawing applies across all drawing practices, digital and analogue. However, post-digital drawing practices shift the craft of drawing from the accumulation of information in a single medium to the quick production of multiple packets of information spread across multiple media. The necessity of post-digital drawing practices is to be literate enough in terms of any new tools or techniques so as to recognise the qualities of craft in them, a necessity that can only occur through practical engagement. The craft of drawing now consists of abilities to shift design content between tools as much as it does to develop design with any one particular tool. The operational discontinuity that is forced through the shifting of design content between collaborators and tools, and the resulting necessity with each shift of reworking the design content, is the means to develop the design. Further, the nature of the shifts - the speed, the levels of precision, the levels of reinterpretation required or pursued - directly impacts upon the design content. It may be argued then that design develops as much between tools as it does within any one tool - in other words, through inter-instrumental operations.

\section{Proposition 3: Differentiate drawing practices}

The assumption that there is a uniform space through which meaning may glide without modification is more than just a naïve delusion however. Only by assuming its pure and unconditional existence in the first place can any precise knowledge of the pattern of deviations from this imaginary condition be gained. (Evans 1997: 154)

The tools and techniques of design have never been neutral. Each is prone to producing particular, often identifiable end qualities. Software is no different. The problem outlined in the introduction of this paper of the "same-ness" and the "tired-ness" of the digital lies neither with the computer nor with software. The problem lies with the users, those who draw with these tools. The issue is not one of digital versus analogue but of the designer's understanding of, and sensitivity toward their instruments and their use - it is about the development of drawing craft.

The challenge is two-fold: to get beyond the interface (Allen 2009), to use the software in a manner which allows the design to remain focal and the development of technique to be secondary, and to establish and exploit connections between 
instruments (digital and analogue) in a generative manner. Success in this regard yields the potential for differentiated drawing practices and outcomes through recombinant configurations of tools and techniques.

\section{Conclusion}

A hybrid digital-analogue drawing practice has been articulated through a discussion of the preliminary design process for the Ecostore project. The discussion has been structured in terms of five strategies the project demonstrates for the maintenance of the abstract critical facility of drawing. Three further propositions with regard to post-digital drawing practices have been extrapolated.

Specialise and collaborate; delay the "real", explore the possible; retain disciplinary specificity; aggregate drawings; expose the diagram ... so the abstract critical facility of drawing was maintained in the Ecostore project.

Draw; shift content; differentiate drawing practices ... to the effect of developing drawing practices that hold the tools and techniques we have at our disposal in a dynamic tension, managing the influence each exerts in relation to the other strategically, according to the stage and nature of the design process.

This collectively may present a sense of the familiar. The digital augmentation of the toolkit at the disposal of designers has not affected aims of achieving an open, explorative and responsive design process for those who carry such a concern. What the digital augmentation of drawing practices may be understood to have provided is more choice in terms of the tools and techniques that may be used in a project. Selection is a question of strategy concerning the potential application of tools and techniques, and potential relationships between them, in relation to the design project as it unfolds. The critical evaluation of one tool or technique relative to another in the project context also brings to drawing practice a greater critical awareness of the agency of the tools and techniques. More tools, more choice, more awareness equates to more dynamism in the relationships between them, and a heightening in the task of managing drawing practice. What this expanded choice and awareness effects is a shift from a focus more trained upon the tools and techniques themselves, to a focus equally trained upon the tools and techniques and the relationships between them.

\section{References}

Allen, S. (1995, 2005). Terminal Velocities: The Computer in the Design Studio. In S. Allen, (2009) Practice: architecture, technique + representation. Expanded $2^{\text {nd }}$ version (70-93). Oxfordshire: Routledge.

Evans, R. (1986). Translations from drawing to building. In R. Evans, (1997). Translations from drawing to building and other essays (153-193). London: Architectural Association.

Lynn, G. (1998). Forms of expression: the proto-functional potential of diagrams in architectural design. In G. Lynn, (1998) Folds, bodies E blobs: collected essays (223-233).Brussels: La lettre volée.

\section{Ecostore project credits}

Project leader: Michael Davis

Assistants: Patrick Loo and Ian Scott

All drawings are by Michael Davis, Patrick Loo and Ian Scott 
Refereed Drawings 